\title{
Correlation and agreement between depressive symptoms in children and their parent's perception
}

\author{
José Luis Ramírez-GarcíaLuna, ${ }^{1,2}$ Paola Araiza-Alba, ${ }^{1}$ Sandra Guadalupe Martínez-Aguiñaga, ${ }^{1}$ \\ Héctor Rojas-Calderón, ' María Mercedes Pérez-Betancourt'
}

Original article

\section{ABSTRACT}

\section{Introduction}

Childhood depression is a disease that is becoming more frequent. Few reports address parental perception of children depressive symptoms, and these studies have not been carried out in community samples.

\section{Objective}

To evaluate the correlation and agreement of depressive symptoms in school-age children, and their parent's perception about emotional and conduct abnormalities.

\section{Method}

A transversal study was performed in 284 children who filled a Children Depression Inventory. One of their parents filled a Strengths and Difficulty Questionnaire, and correlation between scores and subcomponent scores were assessed. Agreement between presence of depressive symptoms in children and their parent's perception of abnormal emotional and/or conduct reports was also obtained.

\section{Results}

47 children were identified with depressive symptoms. We found moderate correlation between scores. We did not find agreement between the presence of depressive symptoms in the children and the report of emotional and conduct abnormalities by parents.

\section{Discussion and conclusion}

There is a modest correlation between depressive symptom severity and parental perception of abnormal emotions and/or behaviors. We found no evidence of agreement between these domains in our study, which suggests that parents fail to perceive negative emotions or conducts as depressive symptoms in their children. Parental reports should be addressed by healthcare workers, and their emotional significance should be interpreted. An intentional search of depressive symptomatology in children should be a priority.

Key words: Depressive symptoms, behavioral symptoms, problem behavior, psychometrics, childhood depression.

\section{RESUMEN}

\section{Introducción}

La prevalencia de la depresión infantil está al alza. Pocos estudios han evaluado la percepción parental de los síntomas depresivos en niños, y los que se han realizado no han sido replicados en la comunidad.

\section{Objetivo}

Evaluar la correlación y la concordancia entre los síntomas depresivos en niños de edad escolar con la percepción de sus padres sobre problemas emocionales y conductas anormales.

\section{Método}

Se realizó un estudio transversal en 284 niños que contestaron el Inventario de Depresión Infantil y se compararon los puntajes con el Cuestionario de Fortalezas y Dificultades que llenó uno de los padres. Se evaluó la correlación entre los puntajes totales y por sub-escalas, así como la concordancia entre la presencia de puntajes sugestivos de depresión infantil y la percepción parental de emociones y conductas anormales.

\section{Resultados}

47 niños fueron identificados con puntajes indicativos de sintomatología depresiva. Encontramos correlación moderada entre los puntajes de las escalas. No encontramos concordancia entre la presencia de síntomas depresivos y el reporte parental de emociones o conductas anormales.

\section{Discusión y conclusión}

Existe correlación entre la severidad de los síntomas depresivos y la percepción parental de emociones y conductas anormales. No encontramos concordancia entre ambas mediciones, lo cual sugiere que los padres fallan al identificar las conductas y emociones anormales de sus hijos como los síntomas depresivos. Los reportes de los padres deben ser tomados en cuenta y ser interpretados por el personal de salud. La búsqueda intencionada de síntomas depresivos en niños debe ser parte fundamental del proceso de cuidado de esta población.

Palabras clave: Síntomas depresivos, síntomas conductuales, conductas problemáticas, psicometría, depresión infantil.

Clínica Psiquiátrica "Dr. Everardo Neumann Peña", Km 8.5 carretera a Matehuala, 78430, San Luis Potosí, México.

2 Research Institute of the McGill University Hospital, 1650 Cedar Ave, Montreal, H3G 1 A4 Quebec, Canada.

Correspondence: José Luis Ramírez-Garcíaluna. Research Institute of the McGill University Hospital, 1650 Cedar Ave, Montreal, H3G 1A4 Quebec, Canada. Tel: +1 (514) 934 - 1934 ext. 42837. E-mail: jose.ramirezgarcialuna@mail.mcgill.ca

Received first version: April 15, 2016. Second version: July 24, 2016. Third version: August 26, 2016. Accepted: August $31,2016$. 


\section{INTRODUCTION}

Childhood onset psychiatric disorders should be a public health priority, since it has been demonstrated that several of them are carried into adulthood where they are associated with risk conducts for addictions and suicide. ${ }^{1}$ In spite of the body of evidence that supports the importance of preemptive programs for the promotion of healthy environments for children, many of them lack access to mental health services, ${ }^{2,3}$ making identification and outreach to vulnerable populations a health concern.

Among childhood, mental disorders onset depression is one of the most common. It is estimated that approximately $20 \%$ of the world population will suffer from it at some point in their life. Projections for the year 2020 place it as the first cause of work non-attendance in developed countries and as the second most common disease worldwide.,4 In children, depression is nowadays the second most frequent psychiatric pathology. Its prevalence has increased from $0.4 \%$ to $2.5 \%$ and its mean age of onset has diminished from 14.9 to 11 years in the last 20 years..$^{5-7}$ School-age boys present this disorder more often than girls, and this relation is inverted to a ratio of 2:1 in adolescence. ${ }^{8}$ In Mexico, it is estimated that $2 \%$ of the population, which roughly represents two million people, has suffered at least one major depressive episode before age 18. Data from this country shows that, among all people who have suffered a major depressive episode at least once in their lifetime, $27.5 \%$ had its first one during childhood or adolescence; and that the mean number of non-major depressive episodes during a person's lifetime is seven. ${ }^{9,10}$

Detection of depressive symptoms in children is often more complicated than in adults. School-age to pubertal children normally show depressive symptoms in one of three spheres: affective/conductive, which is characterized by irritability, aggression, agitation or psychomotor inhibition, asthenia, apathy, recurrent sensation of boredom, guilt, and death thoughts; school related and cognitive symptoms, which includes low school performance, lack of self-esteem, school phobia, conduct disorders in school and with their peers; or in a somatic sphere, characterized by headaches, abdominal pain, sphincter control disorders, sleep disturbances, low weight in relation to their age, and eating disorders. Among all symptoms, the most commonly reported in children are irritability, hyperactivity, and isolation. ${ }^{11,12}$ Making the diagnosis of depression is harder in younger children, since symptoms tend to appear in a mixed pattern, which may parents fail to notice. ${ }^{13}$

Few reports address parental perception of depression or depressive symptoms in their children. In the existing reports, a modest correlation between parental perception and children report is the norm. Parents, teachers, children, and clinicians are often discrepant in how they perceive and rate the child's emotional, and behavioral problems. ${ }^{14,15}$ While children's reports appear to be more consistent with a psychiatrist's diagnosis of depression, parents fail to recognize symptoms. ${ }^{16,17}$ Approximately $60 \%$ of parents fail to perceive problems in their offspring's mental health, especially among children with attention deficit disorder and children with clinically diagnosed depressive disorder. ${ }^{18}$ Discrepancies have an impact on the assessment, classification, and treatment of childhood psychopathology; and are maintained throughout childhood, adolescence and adulthood. ${ }^{19}$ Youth self-harm behavior, which is a manifestation of depression and anxiety, has been found to possess an agreement of $30 \%$ between adolescent self-reports and parental reports; ${ }^{20}$ and there is a discordance of approximately $20 \%$ between parental perception of mental health issues in kindergartens and the results of their screening with a behavior assessment tool. ${ }^{21}$ Even among adults, cross-informant correlations of psychopathology are lower than $0.5 .^{22}$

Most of these studies were done in psychiatric facilities and focus on the presence of psychiatric illness, not on the presence of symptoms, and they have not been replicated in community samples where a broad spectrum of healthy to severely depressed children can be found. Therefore, the objective of this study was to evaluate the correlation of depressive symptoms in school-age children, as assessed by the Children Depression Inventory (CDI), and their parent's perception about emotional and conduct abnormalities, as assessed by the Strengths and Difficulty Questionnaire Spanish ("Castellano") version (SDQ-CAS); as well as to evaluate the diagnostic agreement between these scores.

\section{METHODS}

\section{Patients}

Between June 2014 and February 2015, parents of 3rd to 5th year elementary school children in the city of San Luis Potosí, Mexico were invited to participate in the study. The population sample was selected by convenience in the three largest public elementary schools in the vicinity of our psychiatric clinic. This population corresponds to parents and children of an urban area of middle-low to low socioeconomic status. Since we aimed for a population based study, invitations to participate were extended to all people who met criteria for inclusion: parents who had children aged 8 to 12 years with no history of diagnosed psychiatric disorders, that they were the child's main caregiver, and that they were literate. We obtained the children's clinical history from the parents to rule out prior psychiatric illness after procuring an informed consent. We excluded all children whom parents reported any prior psychological or psychiatric intervention or treatment. Parents were applied the SDQ-CAS test and their children the CDI questionnaire after obtaining their assent. To mini- 
mize the risk of bias, the reports were obtained independently by researchers blinded to the results of the measurements. Children who displayed depressive symptoms through a cutoff value of 18 points in the CDI test were referred to the child psychiatry service of "Dr. Everardo Neumann Peña" psychiatric clinic for their full assessment and treatment, if required. The study was approved by the Ethics Committee of the Institution (registry CEI-CPENP-13-18).

\section{Instruments}

The CDI is a self-applicable test for children between 7 to 17 years that detects depressive symptoms. It is a Likert-type score that has 27 items ranked from 0 to 2; thus, its range value goes from 0 to 54 points. It has been used as a screening test with a reported specificity of $83 \%$, sensitivity of $84 \%$, and a positive predictive value of $40 \%$ for the detection of depression in children. Its cutoff value for the presence of depressive symptoms is 18 points. ${ }^{23,24}$

The SDQ-CAS is also a self-applicable test for parents of children between 3 to 16 years. It detects emotional and conduct abnormalities in their offspring. It is subdivided in 4 potential problems sub scores: emotional symptoms, behavior problems, hyperactivity/lack of attention, peer-relation issues; and one strength sub score of prosocial conduct. It is a Likert-type score that has 25 items (5 per sub score) ranked from 0 to 2 . For its final value, only the potential problems sub scores are taken into account; therefore the report values of the total difficulty score range from 0 to 40 . The score has a specificity of $94 \%$ and a sensitivity of $63 \%$ for the detection of psychiatric disorders in children, and a predictive value of $70 \%$ for the detection of depression. Its cutoff value for an abnormal report is 17 points. ${ }^{25,26}$ For this study, we used the Spanish versions of the CDI and the SDQ-CAS. ${ }^{27,28}$

\section{Statistical analysis}

Through a Shapiro-Wilk test, a normal distribution of the response variables was determined, and since it was ruled out, non-parametric tests were deemed appropriate. To assess differences in CDI-CAS and SDQ scores between schools, Wilcoxon rank-sum tests with Bonferroni correction for multiple comparisons were used. For the correlation between CDI and SDQ-CAS scores, as well as between CDI and each sub score of the SDQ-CAS, Spearman rank correlation tests were used; and afterwards, the effect of children's age and sex co-variables were adjusted by multiple generalized lineal models. For sample size determination, we calculated that 20 observations per degree of freedom of the maximum general lineal model would be enough to avoid overfitting it. ${ }^{29}$ Since the maximum models have 3 degrees of freedom (score $\sim C D I+$ age + sex), we calculated we needed at least 60 pairs of parent and children.
Finally, to assess the agreement between the presence of depressive symptoms, as assessed by CDI scores $\geq 18$, and an abnormal parental report, as assessed by SDQ-CAS scores $\geq$ 17, a Cohen's Kappa test was performed. Statistical analysis was conducted in R v.3.0.2 $2^{30}$ at $95 \%$ confidence interval.

\section{RESULTS}

From 315 pairs of parents and children that met inclusion criteria, 284 were included in the study after signing the consent. 31 parents did not attend to the informative meeting, and did not sign the consent, thus were excluded. No children met the exclusion criteria of having been under prior psychological or psychiatric treatment. Population characteristics are presented in table 1 . We found no statistical significant differences between median scores neither in CDI nor in SDQ-CAS tests according to children's school $(p>.05$ in Wilcoxon sum-rank tests with Bonferroni correction for multiple comparisons).

Forty-seven children were identified with CDI scores above 18 points. We found no significant differences between girls (23.68 \pm 4.2 , median 22.5) and boys (22.12 \pm 2.9 , median 22) $(p=.1)$ in this subgroup.

We found correlation between scores in CDI and SDQCAS tests $\left(\rho_{\mathrm{s}}=.1761,95 \% \mathrm{CI}[.0593, .2771], p=.003\right)$. After adjusting for age and sex of the child in a multiple generalized lineal model we found no significant effects of these variables in the result. For each 1 point increase in the CDI score, there is a .13 point increase in the SDQ-CAS score $95 \%$ CI $[.03, .24]$ (figure 1). We did not find agreement between the presence of depressive symptoms in the children and the report of emotional and conduct abnormalities by parents (kappa $=.0635,95 \%$ CI $[-.0147, .1419])$.

We found correlation between CDI score and the emotional symptoms SDQ-CAS sub score $\left(\rho_{\mathrm{s}}=.1645,95 \% \mathrm{CI}\right.$ $[.0479, .2734], p=.005)$, as well as with the behavior problems SDQ-CAS sub score $\left(\rho_{\mathrm{s}}=.196,95 \%\right.$ CI $[.083, .3074]$, $p<.001)$. We did not find association with the rest of the SDQ-CAS sub scores (table 2).

Table 1. Population characteristics

\begin{tabular}{ll}
\hline Age & $10.13 \pm 0.87$ years \\
Sex & Girls $=118(41.55 \%)$ \\
& Boys $=166(58.45 \%)$ \\
CDI & Median $=11.0($ (IQR 9) points \\
Depressive symptoms & Without depressive symptoms $=237(83.45 \%)$ \\
& With depressive symptoms $=47(16.55 \%)$ \\
SDQ-CAS & Median $=16($ IQR 8$)$ points \\
Emotional symptoms & Normal parent report = $126(44.37 \%)$ \\
and presence & Abnormal parent report $=158(55.63 \%)$ \\
of abnormal behavior &
\end{tabular}

The presence of depressive symptoms was assessed as positive if CDI score $\geq 18$. The parent's report was considered abnormal if SDQ-CAS score was $\geq 17$. 


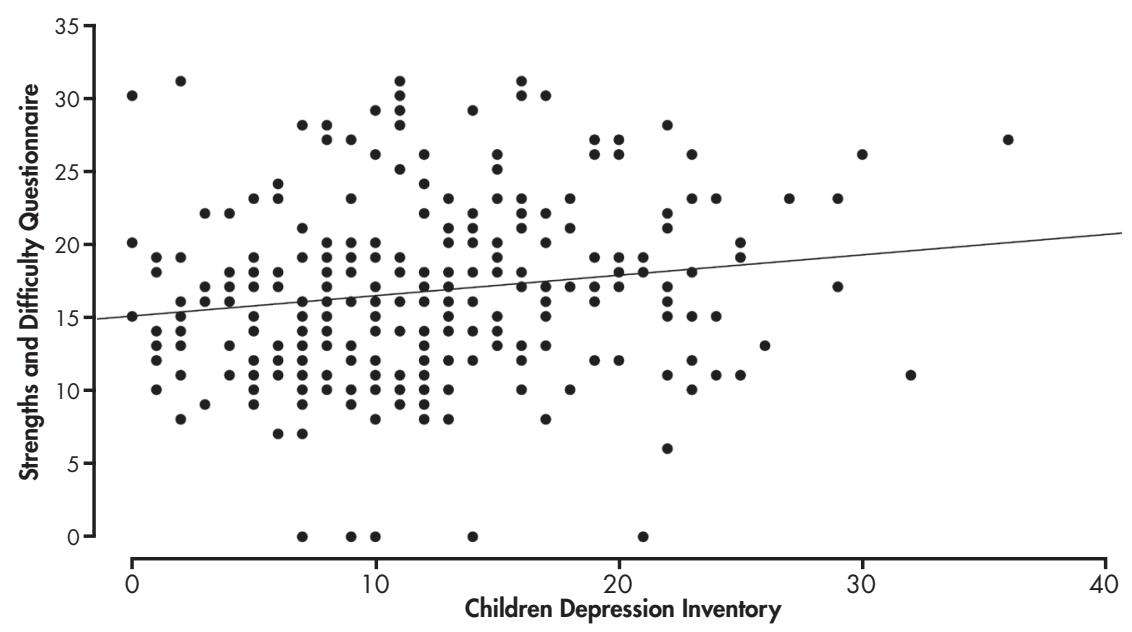

Figure 1. A positive correlation between CDI and SDQ-CAS scores was found $\left(\rho_{s}=.1761\right.$, $p=.003)$. This effect is independent of age and sex of the child.

\section{DISCUSSION AND CONCLUSION}

In this study, we found a prevalence of depressive symptoms in school-age children of $16.55 \%$. Reports from other countries place the prevalence of children depressive symptoms in $10 \%$ to $35 \%, 31,32$ thus our findings are within the expected prevalence for these symptoms. Differences in the prevalence between depressive symptoms and depressive disorder arise from the fact that having symptoms does not necessarily mean that children have the disorder. The CDI instrument was designed to diagnose depressive symptoms in children, not depression; and it is used as a screening test.

A moderate correlation between CDI and SDQ-CAS scores $\left(\rho_{\mathrm{s}}=.1761, p=.003\right)$ may imply that as the depressive symptoms in children become more severe, their parents perceive more severe emotional and conduct abnormalities. Nevertheless, since there is no agreement between the presence of symptoms and the presence of an abnormal report, this may suggest that parents fail to identify the disturbance as depressive symptomatology. The SDQ-CAS sub scores that correlated with depressive symptoms in children were emotional symptoms $\left(\rho_{\mathrm{s}}=.1645, p=.005\right)$ and behavior problems $\left(\rho_{\mathrm{s}}=.1960, p<.001\right)$, which are in agreement with

Table 2. Correlation between CDI Score and SDQ-CAS subcomponent scores

\begin{tabular}{lccc}
\hline Subcomponent & Spearman's Rho & $95 \% \mathrm{Cl}$ & $P$ value \\
\hline Emotional symptoms & .164 & .0479 to .2734 & $.005^{*}$ \\
$\begin{array}{l}\text { Behavior problems } \\
\text { Hyperactivity / lack }\end{array}$ & .196 & .0830 to .3074 & $<.001^{*}$ \\
of attention & .017 & -.1020 to .1380 & .800 \\
Peer-relation issues & .117 & 0 to .2320 & .050 \\
Prosocial conduct & -.058 & -.1620 to .0530 & .300 \\
\hline$*$
\end{tabular}

* $p<.05$. what is described as symptoms of mood disorders in children. These sub scores measure the presence and intensity of somatic symptoms such as headaches, abdominal pain or nausea; aggressiveness, irritability, isolation, anxiety, and restlessness in children. Emotional symptoms and behavioral problems can arise from other psychiatric or psychological conditions, but they may also be proxy symptoms of depression in children. This study was not designed to identify other psychiatric symptoms or behavioral abnormalities, such as attention deficit disorder, anxiety, or eating disorders, and therefore it is probable that the presence of comorbidities or other diagnosis beside depression may have acted as confounding factors that caused the lack of agreement between scores. We were surprised at not having found correlation between depressive symptoms and the hyperactivity / lack of attention SDQ-CAS sub score, as this is one of the main symptoms of depression in children. A possible explanation for this phenomenon is that parents fail to identify these conducts as mood disorders, or that these symptoms are not expressed at home. From our clinical experience, we favor the first hypothesis.

We included an additional reactive for parents, in which they were asked to detail the most disturbing feeling or conduct that they have observed in their child. The most common parent commentaries were that children had developed low academic performance, rebel conducts, aggression or anxiety. Among the children with CDI scores $\geq 18$ the most common reports were isolationism, mood fluctuations, irritability, and suicidal thoughts. It is noteworthy that despite the severity of these symptoms, from 47 children identified with depressive symptoms only 20 of them were taken by their parents into the child psychiatry service. Parents identify more conduct disturbances than moods, which may be an explanation for the unawareness of symptoms in their children. We believe that insufficient understanding of de- 
pression can be a result of poor parental mental health education. Barriers in the emotional communication between parents and children to identify and verbalize emotions may be overcome by psychoeducation. This may be the best strategy for the prevention and for the correct identification of depressive symptoms and disorders in childhood, as well as to avert suicides among children and adolescents. ${ }^{33,34}$ Discrepancies in children and parental report of psychiatric symptomatology may arise because of the children's age, their ability to describe feelings and behaviors, and their fear of rejection. ${ }^{15}$ They may also arise from parent characteristics, such as attempts to conceal disruptive behaviors, family issues, or parental psychopathology. ${ }^{35}$ Our study supports the notion that the best way to avoid misdiagnosing children is by taking into account reports from multiple sources. ${ }^{19}$

Our study possesses several limitations. First, while we believe that the lack of agreement between parent and child scores reflects poor parental perception, it can also mean that the cutoffs (18 points for CDI and 17 points for SDQCAS) are somehow invalid. Since the diagnosis of depressive disorder in this study was not explored through a clinical assessment, we cannot assess this claim and we consider it to be our main limitation. We were interested only in symptoms, not in depressive disorder; therefore we did not make an independent assessment of the diagnosis of depression. Nevertheless, both instruments are widely used for this purpose and their diagnostic accuracy is considered acceptable for diagnosing child depressive disorder (CDI) and conduct abnormalities (CDQ-CAS). ${ }^{23,26}$ Second, several situations that may act as triggers for depressive symptoms, and that could interfere in the parental perception of abnormal emotions or behaviors in their children, such as family dysfunction, family violence, migratory phenomena, and addictions, were not recorded. Furthermore, the SDQ test has been shown to identify other psychiatric disorders. The questionnaire identifies approximately $70 \%$ of individuals with conduct, hyperactivity, depressive and anxiety disorders, but under $50 \%$ of individuals with phobias, separation anxiety or eating disorders. Thus, this could have acted as a confounding factor. Third, parental mental health was not assessed, and it has been described to be an important factor in the development of emotional and behavioral problems in children, especially if parents display depressive symptoms. ${ }^{36}$ This effect can be explained both from a genetic point of view, and from ambient exposure, which seems to be more important. ${ }^{37}$ Although this factor was not addressed in our study and it can potentially bias the interpretation of the lack of agreement between the presence of child depressive symptoms and parental perception, our interpretation is that parents do perceive that their children have conduct abnormalities, since there is correlation between CDI and SDQ-CAS scores. However, they fail to identify the conduct abnormalities as depressive symptoms, which could explain the lack of agreement between measurements. Further studies must address what is exactly what parents perceive as abnormal, and how this correlates with mental health of both parties. Finally, our sample comes from urban public schools with middle-low to low socioeconomic levels, thus our findings are restricted to this population, and the absence of control of confounding factors may compromise the applicability of our findings to other populations. According to data from the latest Mexican census, less than $5 \%$ of the children aged 10 to 11 years old in the State of San Luis Potosí, Mexico, do not attend to school. ${ }^{38}$ We believe that, while it is very likely that these children may exhibit poor mental health due to the factors discussed above, our results can be extrapolated to most children who meet the inclusion criteria.

Future directions from our work could be to assess and compare the perception of child's depressive symptoms between parents and teachers and to perform similar analysis in adolescents and their peers, as well as to address the limitations' concerns.

In conclusion, our results suggest that even though, there is correlation between CDI and SDQ-CAS scores; there is no agreement between the presences of abnormal reports in them. For the evaluation and diagnosis of childhood psychiatric disorders, the parents' interviews are a cornerstone to complement and validate the children's reports. Our results suggest that the weight of these reports should be taken with more caution when they are negative, and that clinicians should try to give an emotional significance to the conducts reported by the parents. An intentional search of depressive symptomatology in children, specifically in the pediatrician's office, must be a priority for mental health welfare, since it is very likely that parents will not perceive symptoms until their child presents their most severe manifestations, such as self-harming or suicide attempts.

\section{Funding}

The authors confirm that there has been no significant financial support that could have influenced the outcome of this work.

\section{Conflict of interest}

The authors confirm that there are no known conflicts of interest associated with this work.

\section{Acknowledgments}

The authors would like to acknowledge the Education Ministry of San Luis Potosí, Mexico, for its kind assistance with this research project, especially through Professor Antonio F. Gallegos García.

\section{REFERENCES}

1. Vicente B, de la Barra F, Saldivia S, Kohn R, Rioseco P, Melipillan R. Prevalence of child and adolescent psychiatric disorders in Santiago, Chile: a community epidemiological study. Soc Psychiatry Psychiatr Epidemiol. 2012;47(7):1099-1109.

2. National Research Council (US) and Institute of Medicine (US) Committee on the Prevention of Mental Disorders and Substance Abuse Among 
Children, Youth, and Young Adults: Research Advances and Promising Interventions. Preventing Mental, Emotional, and Behavioral Disorders Among Young People: Progress and Possibilities [Internet]. O'Connell ME, Boat T, Warner KE, editors. Washington (DC): National Academies Press (US); 2009 [cited 2015 Jun 10]. (The National Academies Collection: Reports funded by National Institutes of Health). Available from: http://www.ncbi.nlm.nih.gov/books/NBK32775/

3. WHO | Mental health action plan 2013 - 2020 [Internet]. WHO. [cited 2015 Jun 10]. Available from: http://www.who.int/mental_health/publications/action_plan/en/

4. Kohn R, Levav I, Almeida JMC de, Vicente B, Andrade L, Caraveo-Anduaga JJ, et al. Mental disorders in Latin America and the Caribbean: a public health priority. Rev Panam Salud Pública 2005;18(4-5):229-240.

5. Lewinsohn PM, Clarke GN, Seeley JR, Rohde P. Major depression in community adolescents: age at onset, episode duration, and time to recurrence. J Am Acad Child Adolesc Psychiatry 1994;33(6):809-818.

6. Whitaker A, Johnson J, Shaffer D, Rapoport JL, Kalikow K, Walsh BT, et al. Uncommon troubles in young people: prevalence estimates of selected psychiatric disorders in a nonreferred adolescent population. Arch Gen Psychiatry 1990;47(5):487-496.

7. Benjet C, Borges G, Medina-Mora ME, Méndez E, Fleiz C, Rojas E, et al. Diferencias de sexo en la prevalencia y severidad de trastornos psiquiátricos en adolescentes de la Ciudad de México. Salud Ment 2009;32(2):155-163.

8. Rafful C, Medina-Mora ME, Borges G, Benjet C, Orozco R. Depression, gender, and the treatment gap in Mexico. J Affect Disord 2012;138(1-2):165-169.

9. Benjet C, Borges G, Medina-Mora ME, Fleiz-Bautista C, Zambrano-Ruiz J. [Early onset depression: prevalence, course, and treatment seeking delay]. Salud Publica México 2004;46(5):417-424.

10. Berenzon S, Lara MA, Robles R, Medina-Mora ME. [Depression: state of the art and the need for public policy and action plans in Mexico]. Salud Publica México 2013;55(1):74-80.

11. Wiley: Rutter's Child and Adolescent Psychiatry, 5th Edition - Michael Rutter, Dorothy Bishop, Daniel Pine, et al [Internet]. [cited 2015 Jun 10]. Available from: http://www.wiley.com/WileyCDA/WileyTitle/productCd-1405145935.html

12. Bettge S, Wille N, Barkmann C, Schulte-Markwort M, Ravens-Sieberer U, BELLA study group. Depressive symptoms of children and adolescents in a German representative sample: results of the BELLA study. Eur Child Adolesc Psychiatry 2008;17 Suppl1:71-81.

13. Zukauskiene R, Pilkauskaite-Valickiene $R$, Malinauskiene $O$, Krataviciene R. Evaluating behavioral and emotional problems with the Child Behavior Checklist and Youth Self-Report scales: cross-informant and longitudinal associations. Med Kaunas Lith 2004;40(2):169-177.

14. De Los Reyes A, Henry DB, Tolan PH, Wakschlag LS. Linking informant discrepancies to observed variations in young children's disruptive behavior. J Abnorm Child Psychol 2009;37(5):637-652.

15. Grills AE, Ollendick TH. Issues in parent-child agreement: the case of structured diagnostic interviews. Clin Child Fam Psychol Rev 2002;5(1):57-83.

16. Moretti MM, Fine S, Haley G, Marriage K. Childhood and adolescent depression: child-report versus parent-report information. J Am Acad Child Psychiatry 1985;24(3):298-302.

17. Kazdin AE, Petti TA. Self-report and interview measures of childhood and adolescent depression. J Child Psychol Psychiatry 1982;23(4):437457.

18. Teagle SE. Parental problem recognition and child mental health service use. Ment Health Serv Res 2002;4(4):257-266.

19. De Los Reyes A, Kazdin AE. Informant discrepancies in the assessment of childhood psychopathology: a critical review, theoretical framework, and recommendations for further study. Psychol Bull 2005;131(4):483-509.
20. Mojtabai R, Olfson M. Parental detection of youth's self-harm behavior. Suicide Life Threat Behav 2008;38(1):60-73.

21. Girio-Herrera E, Owens JS, Langberg JM. Perceived barriers to help-seeking among parents of at-risk kindergarteners in rural communities. J Clin Child Adolesc Psychol Off J Soc Clin Child Adolesc Psychol Am Psychol Assoc Div 53. 2013;42(1):68-77. doi: 10.1080/15374416.2012.715365

22. Achenbach TM, Krukowski RA, Dumenci L, Ivanova MY. Assessment of adult psychopathology: meta-analyses and implications of cross-informant correlations. Psychol Bull 2005;131(3):361-382.

23. Stockings E, Degenhardt L, Lee YY, Mihalopoulos C, Liu A, Hobbs M, et al. Symptom screening scales for detecting major depressive disorder in children and adolescents: a systematic review and meta-analysis of reliability, validity and diagnostic utility. J Affect Disord 2015;174:447-463.

24. Sun S, Wang S. The Children's Depression Inventory in Worldwide Child Development Research: A Reliability Generalization Study. J Child Fam Stud 2014;24(8):2352-2363.

25. Goodman R. The Strengths and Difficulties Questionnaire: a research note. J Child Psychol Psychiatry 1997;38(5):581-586.

26. Goodman R, Ford T, Simmons H, Gatward R et al. Using the Strengths and Difficulties Questionnaire (SDQ) to screen for child psychiatric disorders in a community sample. Br J Psychiatry J Ment Sci 2000;177: 534-539.

27. Masip AF, Amador-Campos JA, Gómez-Benito J, Gándara V del B. Psychometric properties of the children's depression inventory in community and clinical sample. Span J Psychol 2010;13(02):990-999.

28. Gómez-Beneyto M, Nolasco A, Moncho J, Pereyra-Zamora P et al. Psychometric behaviour of the strengths and difficulties questionnaire (SDQ) in the Spanish national health survey 2006. BMC Psychiatry 2013;13(1):95.

29. Babyak MA. What you see may not be what you get: a brief, nontechnical introduction to overfitting in regression-type models. Psychosom Med 2004;66(3):411-421.

30. R Core Team R. A language and environment for statistical computing [Internet]. Vienna, Austria: R Foundation for Statistical Computing; 2016. Available from: http://www.R-project.org/

31. Boyd CP, Kostanski M, Gullone E, Ollendick TH et al. Prevalence of anxiety and depression in Australian adolescents: comparisons with worldwide data. J Genet Psychol 2000;161(4):479-492.

32. Magiati I, Ponniah K, Ooi YP, Chan YH et al. Self-reported depression and anxiety symptoms in school-aged Singaporean children. Asia-Pac Psychiatry Off J Pac Rim Coll Psychiatr 2015;7(1):91-104.

33. Joshi SV, Hartley SN, Kessler M, Barstead M. School-based suicide prevention: content, process, and the role of trusted adults and peers. Child Adolesc Psychiatr Clin N Am 2015;24(2):353-370.

34. Walrath C, Garraza LG, Reid H, Goldston DB et al. Impact of the Garrett Lee Smith youth suicide prevention program on suicide mortality. Am J Public Health 2015;105(5):986-993.

35. Reyes ADL, Goodman KL, Kliewer W, Reid-Quiñones K. Whose depression relates to discrepancies? Testing relations between informant characteristics and informant discrepancies from both informants' perspectives. Psychol Assess 2008;20(2):139-149.

36. Weitzman M, Rosenthal DG, Liu Y-H. Paternal depressive symptoms and child behavioral or emotional problems in the United States. Pediatrics 2011;128(6):1126-1134.

37. McAdams TA, Rijsdijk FV, Neiderhiser JM, Narusyte J et al. The relationship between parental depressive symptoms and offspring psychopathology: evidence from a children-of-twins study and an adoption study. Psychol Med 2015;45(12):2583-2594.

38. Consulta interactiva de datos [Internet]. [cited 2016 Jul 24]. Available from: http://www.inegi.org.mx/lib/olap/consulta/general_ver4/MDXQueryDatos.asp?c=27781 